e-journal Keperawatan (e-Kp) Volume 7 Nomor 1, Februari 2019

\title{
HUBUNGAN MEKANISME KOPING DENGAN STRES KERJA PERAWAT DI RSU GMIM BETHESDA TOMOHON
}

\author{
Grace Jinny Mundung \\ B H Ralph Kairupan \\ Rina Kundre \\ Program Studi Ilmu Keperawatan Fakultas Kedokteran \\ Universitas Sam Ratulangi \\ Email :gracemundung3@gmail.com
}

\begin{abstract}
Stress is an epidemic that spreads throughout the world according to the World Health Organization. Stress occurs in Asian countries Survey from PPNI in 2006, around $50.9 \%$ of nurses, worked in 4 provinces in Indonesia. Objective :this research is to know the correlation between coping mechanisms with job stress in nurses at general hospital GMIM Bethesda Tomohon. Research Design : Type of this research is quantitative and using descriptive analytic research method with cross sectional approach. The sampling technique using probability sampling, stratified random sampling method and to determine the sample size, using the Slovin formula and obtained a sample of 53 respondents. Research Result : This research used the Kolmogorov-Smirnov test at a significant level of 95\% which found that a significant value was 0.001 . Conclusion : results of this research indicate that there is a correlation between coping mechanisms and job stress in nurses at general hospital GMIM Bethesda Tomohon.
\end{abstract}

Keywords: Nurse, Coping Mechanisms, Job Stress

Abstrak :Menurut World Health Organization stres merupakan epidemi yang menyebar ke seluruh dunia. Stres terjadi di negara-negara Asia. Survei dari PPNI tahun 2006, sekitar $50,9 \%$ perawat yang bekerja di 4 provinsi di Indonesia mengalami stres kerja. Tujuan : penelitian ini bertujuan untuk mengetahui hubungan mekanisme koping dengan stres kerja perawat di RSU GMIM Bethesda Tomohon. Desain penelitian : jenis penelitian kuantitatif menggunakan metode penelitian deskriptif analitik dengan pendekatan cross sectional. Teknik pengambilan sampel probability sampling metode stratified random sampling dan untuk menentukan besar sampel menggunakan rumus Slovin, didapat jumlah sampel sebanyak 53 responden. Hasil penelitian : menggunakan uji Kolmogorov-smirnov pada tingkat kemaknaaan 95\% di dapat bahwa nilai signifikan adalah 0.001. Kesimpulan : hasil penelitian ini menunjukkan terdapat hubungan antara mekanisme koping dengan stres kerja perawat di RSU GMIM Bethesda Tomohon.

Kata Kunci: Perawat, Mekanisme Koping, Stres Kerja 


\section{PENDAHULUAN}

Menurut World Health Organization (WHO) stres merupakan epidemi yang menyebar ke seluruh dunia. Menurut Donsu Jenita (2017) Stres merupakan interaksi individu dengan lingkungannya, yang saling memengaruhi. Berdasarkan survei atas pekerja tenaga perawat pelaksana di Amerika Serikat ditemukan, $46 \%$ merasakan pekerjaan mereka penuh dengan stres dan $34 \%$ berpikir serius untuk keluar dari pekerjaan mereka 12 bulan sebelumnya karena stres ditempat kerja. (Fajrillah, Nurfitriani, 2015).Survei dari PPNI tahun 2006, sekitar 50,9\% perawat yang bekerja di 4 provinsi di Indonesia mengalami stres kerja. (Fajrillah, Nurfitriani, 2015). MenurutPrasetyo Wijar (2017) di Indonesia kejadian stres kerja perawat pelaksana, di ruang rawat inap di Rumah Sakit Husada diperoleh 44\%, $51,5 \%$ perawat di Rumah Sakit Internasional MH. Thamrin Jakarta, 54\% perawat di Rumah Sakit PELNI "Petamburan" Jakarta serta 51,2\% perawat di Intensive Care Unit (ICU) dan Instalasi Gawat Darurat (IGD) Rumah Sakit Mitra Keluarga Bekasi.

Profesiperawat rentan terhadap stres. Setiap hari, dalam melaksanakan pengabdiannya seorang perawat tidak hanya berhubungan dengan pasien, tetapi juga dengan keluarga pasien, teman pasien, rekan kerja perawat, dokter dan peraturan di tempat kerja serta beban kerja yang terkadang dinilai tidak sesuai dengan kondisi fisik, psikis dan emosionalnya (Almasitoh, 2012). Selain permasalahan tersebut, permasalahan lain yang dapat menimbulkan stres yaitu keterbatasan sumber daya manusia, dimana banyaknya tugas belum diimbangi dengan jumlah tenaga perawat yang memadai. Jumlah perawat dengan jumlah pasien yang tidak seimbang akan menyebabkan kelelahan dalam bekerja karena kebutuhan pasien terhadap pelayanan perawat lebih besar dari standar kemampuan perawat. Kondisi seperti inilah akan berdampak pada keadaan psikis perawat seperti lelah, emosi, bosan, perubahan mood dan dapat menimbulkan stres perawat. (Ambarawati Diah, 2014).

Mekanisme koping merupakan cara yang dilakukan dalam menyelesaikan suatu masalah, menyesuaikan diri dengan perubahan, serta respon terhadap situasi yang mengancam diri, upaya individu dapat berupa perubahan lingkungan yang bertujuan untuk menghilangkan stres yang dihadapi (Munthe, 2014). Hasil penelitian terdahulu tentang mekanisme koping perawat didapatkan responden mempunyai koping positif terhadap stressor kerja yaitu (97\%). Koping yang berfokus pada masalah secara umum dari hasil penelitian di dapatkan bahwa perawat yang menunjukan koping positif yaitu (100\%). Hal ini disebabkan karena perawat menganggap stressor wajar atau rendah. Dan secara psikologis perawat menganggap masalah mudah diselesaikan, karena pendidikan perawat yang sudah tinggi serta pengalaman yang banyak. Koping yang berfokus pada emosi dari hasil penelitian didapatkan bahwa koping perawat menunjukan positif yaitu $100 \%$ (Noer Aini, 2013).

Berdasarkan studi pendahuluan wawancara dengan perawat yang ada di RSU GMIM Bethesda Tomohon didapatkan jumlah total perawat RSU GMIM Bethesda Tomohon adalah 149 perawat, yang terbagi di tiap ruangan pelayanan, dan struktural. Dalam pelayanan menggunakan metode tim dan setiap shift terdiri dari 2 sampai 3 perawat Jadwal dinas perawat di ruangan yaitu 1 hari dinas pagi, 1 hari dinas sore, 1 hari dinas malam, dan 1-2 hari libur. Pembagian jadwal diatur oleh masing masing kepala ruangan. Jika pasien banyak perawat harus bekerja ekstra dalam menangani pasien-pasien karena jumlah perawat yang tidak sesuai dengan pasien yang ada sehingga perawat mengatakan mengalami stres dengan keadaan tersebut. Sehingga dari fenomena yang ada maka peneliti tertarik untuk mengadakan penelitian mengenai "Hubungan 
Mekanisme Koping Dengan Stres Kerja Perawat Di RSU GMIM Bethesda Tomohon".

\section{METODE PENELITIAN}

Jenis penelitian ini yaitu penelitian kuantitatif menggunakan metode penelitian deskriptif analitik. Pengumpulan data dilakukan dengan pendekatan cross sectional. Penelitian dilaksanakan di RSU GMIM Bethesda Tomohon di ruangan rawat inap khususnya di ruangan Bethesda, Yohanes, Markus, Elisabet dan Jeheskiel, pada bulan Oktober - November 2018. Populasi sebanyak 149 orang. Pengambilan sampel pada penelitian inidilakukan secara probability sampling dengan teknik stratified random sampling. Penentuan besar sampel menggunakan rumus Slovin di dapatkan sampel pada penelitian ini adalah 53 orang.yang telah memenuhi kriteria inklusi : Perawat yang bekerja di ruangan rawat inap RSU GMIM Bethesda Tomohon, Perawat yang bersedia menjadi responden, Perawat yang telah bekerja $\geq 1$ tahun. Kriteria eksklusi : Perawat yang bekerja di ruangan perawatan bayi, anak, kebidanan dan kandungan, Perawat yang menduduki jabatan struktural dan juga kepala ruangan, Perawat yang tidak masuk kerja atau cuti kerja.

Penelitian ini menggunakan
instrument yang pertama karakterisik responden terdiri dari 5 pertanyaan, meliputi umur, jenis kelamin, tingkat pendidikan dan lama kerja, kedua stres kerja Kuesioner ini terdiri dari 16 pernyataan yaitu : sering terjadi, kadang terjadi, jarang terjadi, dan tidak pernah, dengan menggunakan tanda check list. Jika responden menjawab sering terjadi (nilai 4), kadang terjadi (nilai 3), jarang terjadi (nilai 2), dan tidak pernah (nilai 1). Untuk interpretasi hasil ukur, jika nilai skor total 16-32 : stres ringan, 33-48 : stres sedang, dan 49-64 : stres berat, ketiga mekanisme koping terdiri dari 15 pernyataan, dengan pilihan jawaban "ya" dan "tidak". Peneliti akan memberikan skor 1 pada jawaban "ya" dan skor 0 untuk jawaban "tidak". Untuk interpretasi Maladaptif : Apabila mendapat nilai 0-8, Adaptif : Apabila mendapat nilai 9-15.

Data yang digunakan pada penelitian ini adalah data primer dan data sekunder. Data primer adalah data yag diperoleh secara langsung dari responden dan data sekunder adalah data yang diperoleh dari pihak RSU GMIM Bethesda Tomohon.Pengolahan data yang diperoleh dari penelitian ini diolah secara manual dengan mengelompokan hasil dari lembar kuesioner yang dibagikan selanjutnya dilakukan analisis menggunakan uji statistik.setelah itu diolah menggunakan sistem komputerisasi, tahap-tahap tersebut yaitu editing, coding, processing, dan cleaning.

Analisis univariat pada penelitian ini akan menghasilkan distribusi frekuensi yang memberi gambaran mengenai jumlah dan presentase. Analisis univariat dilakukan untuk menganalisis karakteristik responden, variabel mekanisme koping dan variabel stress kerja. Analisis bivariat merupakan analisis hasil dari variabel independen diduga memiliki hubungan dengan variabel dependen. Analisis yang digunakan adalah hasil tabulasi silang. Untuk menguji hipotesa dilakukan analisis statistik dengan menggunakan uji statistik chi square pada tingkat kemaknaan $95 \%$ (p - Value< 0.05) setelah diuji hasil tidak memenuhi syaratdan dilanjutkan dengan uji Kolmogorov-Smirnov. Hasil uji statistik Kolmogorov-Smirnov diperoleh nilai $\mathrm{p}$ kurang dari $\alpha(\mathrm{p}=0.001<\alpha=0.05)$, maka dengan demikian dapat dikatakan bahwa Ha diterima yaitu terdapat hubungan antara mekanisme koping dengan stres kerja perawat di RSU GMIM Bethesda Tomohon. 
e-journal Keperawatan (e-Kp) Volume 7 Nomor 1, Februari 2019

HASIL dan PEMBAHASAN

Tabel 1. Distribusi FrekuensiBerdasarkan Jenis Kelamin Responden Di RSU GMIM Bethesda Tomohon November, 2018

\begin{tabular}{ccc}
\hline Jenis Kelamin & $\mathbf{n}$ & $\mathbf{\%}$ \\
\hline Laki-Laki & 5 & 9.4 \\
Perempuan & 48 & 90.6 \\
\hline Total & $\mathbf{5 3}$ & $\mathbf{1 0 0 . 0}$
\end{tabular}

Sumber : Data Primer, 2018

Berdasarkan 53 responden yang diteliti menunjukkan bahwa sebagian besar responden berjenis kelamin perempuan sebanyak 48 orang $(90.6 \%)$.Karena umumnya perawat yang ada di RSU GMIM Bethesda Tomohon berjenis kelamin perempuan. Menurut Wulandari (2012) mengatakan jenis pekerjaan perawat digambarkan sebagai pekerjaan yang cenderung sebagai pekerjaan perempuan.

Tabel 2. Distribusi Frekuensi Berdasarkan Umur Responden Di RSU GMIM Bethesda Tomohon November, 2018

\begin{tabular}{ccc}
\hline Umur & n & \% \\
\hline Remaja & 10 & 18.9 \\
Dewasa Awal & 19 & 35.8 \\
Dewasa Akhir & 12 & 22.6 \\
Lansia Awal & 12 & 22.6 \\
\hline Total & $\mathbf{5 3}$ & $\mathbf{1 0 0 . 0}$
\end{tabular}

Sumber : Data Primer, 2018

Hasil penelitian dari 53 responden yang diteliti menunjukkan bahwa sebagian besar berumur 26-35 tahun (dewasa awal) yaitu sebanyak 19 orang $(35.8 \%)$. Umur yaitu lama hidup yang terhitung mulai saat dilahirkan sampai berulang tahun terakhir. Semakin bertambah umur seseorang maka akan meningkat kedewasaannya, kematangan jiwanya, dan kemampuan dalam melaksanakan tugasnya. Individu dengan umur yang lebih tua mengalami stres yang lebih rendah karena pengalamannya dalam menghadapi stres sudah lebih baik dibandingkan yang berumur muda (Nurazizah, 2017).
Tabel 3. Distribusi Frekuensi Berdasarkan Status Pernikahan Responden Di RSU GMIM Bethesda Tomohon November, 2018

\begin{tabular}{ccc}
\hline Status Pernikahan & n & \% \\
\hline Belum Menikah & 15 & 28.3 \\
Menikah & 38 & 71.7 \\
\hline Total & $\mathbf{5 3}$ & $\mathbf{1 0 0 . 0}$ \\
\hline
\end{tabular}

Sumber: Data Primer, 2018

Data yang diperoleh dari 53 responden yang diteliti menunjukkan bahwa sebagian besar responden sudah menikah yaitu sebanyak 38 orang $(71.7 \%)$. Individu yang berstatus belum menikah lebih beresiko tinggi mengalami stres kerja. Hal ini disebabkan karena pekerja yang berstatus menikah mendapatkan dukungan emosional dari pasangannya (Nurazizah, 2017). Akan tetapi pengaruh status pernikahan terhadap stres kerja hanya akan berpengaruh postif apabila pernikahan tersebut berjalan dengan baik (Karima, 2014).

Tabel 4. Distribusi Frekuensi Berdasarkan Masa Kerja Responden Di RSU GMIM Bethesda Tomohon November, 2018

\begin{tabular}{ccc}
\hline Masa Kerja & n & \% \\
\hline$\leq 2$ & 11 & 20.8 \\
$3-14$ & 19 & 35.8 \\
$15-25$ & 8 & 15.1 \\
$>26$ & 15 & 28.3 \\
\hline Total & $\mathbf{5 3}$ & $\mathbf{1 0 0 . 0}$
\end{tabular}

Sumber : Data Primer, 2018

Berdasarkan 53 responden yang diteliti menunjukkan bahwa mayoritas responden dengan masa kerja 3 - 14 tahun ada 19 orang (35.8\%).Masa kerja berkaitan dengan pengalaman kerja, yaitu berbagai peristiwa yang dialami seseorang selama bekerja, dan dapat dijadikan pengalaman dalam meningkatkan kualitas pekerjaan. (Jusnimar, 2012). Perawat dengan masa kerja lebih lama akan meningkatkan keterampilan seseorang dalam bekerja, semakin mudah dalam menyesuaikan pekerjaanya sehingga semakin bisa menghadapi tekanan dalam bekerja (Sugeng, 2015). 
Tabel 5. Distribusi Frekuensi Berdasarkan Mekanisme Koping Responden Di RSU GMIM Bethesda Tomohon November, 2018

\begin{tabular}{ccc}
\hline Mekanisme Koping & n & \% \\
\hline Maladaptif & 19 & 35.8 \\
Adaptif & 34 & 64.2 \\
\hline Total & $\mathbf{5 3}$ & $\mathbf{1 0 0 . 0}$
\end{tabular}

Sumber : Data Primer, 2018

Hasil penelitian dari 53 responden yang diteliti terlihat bahwa responden kategori mekanisme koping terbanyak yaitu kategori Adaptif sebanyak 34 orang $(64.2 \%)$ dan paling sedikit kategori Maladaptif sebanyak 19 orang (35.8\%). Menurut Munthe (2014) mengemukakan bahwa mekanisme koping merupakan suatu cara pemecahan masalah dimana bila didalam tubuh mengalami ketegangan dalam kehidupan, mengakibatkan mekanisme koping dalam tubuh berfungsi untuk meredakan ketegangan tersebut.

Tabel 6. Distribusi Frekuensi Berdasarkan Stres Kerja Responden Di RSU GMIM Bethesda Tomohon November, 2018

\begin{tabular}{ccc}
\hline Stres Kerja & n & \% \\
\hline Ringan & 10 & 18.9 \\
Sedang & 32 & 60.4 \\
Berat & 11 & 20.8 \\
\hline Total & $\mathbf{5 3}$ & $\mathbf{1 0 0 . 0}$ \\
\hline
\end{tabular}

Sumber : Data Primer, 2018

Data yang diperoleh dari 53 responden yang diteliti terlihat bahwa responden kategori Stres Kerja terbanyak yaitu kategori sedang sebanyak 32 orang $(60.4 \%)$ dan paling sedikit kategori ringan sebanyak 10 orang (18.9\%).Menurut Febriani Sri (2017) stres kerja adalah suatu kondisi ketegangan yang memengaruhi proses berpikir, emosi, dan kondisi seseorang, hasilnya stres yang terlalu berlebihan dapat mengancam kemampuan seseorang dalam menghadapi lingkungan dan pada akhirnya akan mengganggu pelaksanaan tugas-tugasnya.
Tabel 7. Hubungan Mekanisme Koping dengan Stres Kerja Perawat di RSU GMIM Bethesda Tomohon

\begin{tabular}{|c|c|c|c|c|c|}
\hline \multirow{3}{*}{$\begin{array}{c}\text { Mekanisme } \\
\text { Koping }\end{array}$} & \multicolumn{3}{|c|}{ Stres Kerja } & \multirow{3}{*}{ Total } & $\mathbf{p}$ \\
\hline & Ringan & Sedang & Berat & & \multirow{5}{*}{0.001} \\
\hline & $\mathrm{n}$ & $\mathrm{n}$ & $\mathrm{n}$ & & \\
\hline Adaptif & 10 & 24 & 0 & 34 & \\
\hline Maladaptif & 0 & 8 & 11 & 19 & \\
\hline Total & 10 & 32 & 11 & 53 & \\
\hline
\end{tabular}

Sumber : Data Primer, 2018

Data yang diperoleh terlihat jumlah responden mekanisme koping kategori adaptif dengan stres kerja ringan sebanyak 10 orang (29.4\%), mekanisme koping adaptif dengan stres kerja sedang sebanyak 24 orang $(70.6 \%)$, mekanisme koping kategori maladaptif dengan stres kerja sedang sebanyak 8 orang $(42.1 \%)$ dan mekanisme koping kategori maladaptif dengan stres kerja berat sebanyak 11 orang (57.9\%). Hasil penelitian dengan jumlah 53 responden di RSU GMIM Bethesda Tomohon didapatkan hasil pengolahan data yang menggunakan perhitungan uji statistik Kolmogorov-Smirnov dengan menggunakan aplikasi statistik komputer diperoleh nilai $\mathrm{p}$ kurang dari $\alpha(\mathrm{p}=0.001<$ $\alpha=0.05$ ), maka dengan demikian dapat dikatakan bahwa terdapat hubungan antara mekanisme koping dengan stres kerja perawat di RSU GMIM Bethesda Tomohon.

Berdasarkan penelitian yang telah dilakukan di RSU GMIM Bethesda Tomohon diketahui bahwa dalam menghadapi permasalahan responden lebih menggunakan hal-hal yang positif seperti lebih sering mengungkapkan kepada orang lain atau bertukar pendapat dan mereka juga melakukan aktivitas-akivitas yang konstruktif. Sedangkan stres kerja yang dialami responden mayoritas mengalami stres kerja sedang. Hal ini disebabkan karena beberapa faktor yaitu pertama, tidak seimbangnya jumlah perawat dengan jumlah pasien yang ada, tahun 2018 RSU GMIM Bethesda Tomohon memiliki BOR 77,28\% dengan 206 tempat tidur. Kedua, peralatan dan perlengkapan yang terbatas sehingga menghambat kerja perawat dan 
dapat menimbulkan stres kerja. Ketiga, konflik di tempat kerja antara perawat dengan sesama perawat ataupun tenaga kesehatan lainnya atau juga keluarga pasien.

\section{SIMPULAN}

Hasil dari penelitian tentang hubungan mekanisme koping dengan stres kerja perawat di RSU GMIM Bethesda Tomohon tahun 2018. Bahwa sebagian besar responden memiliki mekanisme koping adaptif dan sebagian besar responden mengalami stres kerja sedang. Ada hubungan antara mekanisme koping dengan stres kerja perawat.

\section{DAFTAR PUSTAKA}

Almasitoh, U. H. (2012). Stres kerja ditinjau dari konflik peran ganda dan dukungan sosial pada perawat.

Ambarwati, D., \& Lataruva, E. (2014). Pengaruh Beban Kerja terhadap Stres Perawat IGD dengan Dukungan Sosial sebagai Variabel Moderating (Studi pada RSUP Dr. Kariadi Semarang) (Doctoral dissertation, Fakultas Ekonomika dan Bisnis).

Donsu, J D T. (2017). Psikologi Keperawatan. Yogyakarta: Pustaka Baru Press.

Fajrillah, F., \& Nurfitriani, N. (2015). Hubungan Stres Kerja dengan Kinerja Perawat Pelaksana dalam Melaksanakan Pelayanan Keperawatan di Instalasi Gawat Darurat Rumah Sakit Umum Anutapura Palu. Jurnal Keperawatan Sriwijaya,3(2), 1724.

Febriani, S. (2017) Gambaran Stres Kerja Pada Perawat Di Ruang Rawat Inap Bagian Perawatan Jiwa Rumah Sakit Khusus Daerah Provinsi Sulawesi Selatan Tahun 2017.

Jusnismar. (2012). Gambaran Tingkat Stres Kerja Perawat Intensive Care
Unit Di Rumah Sakit Kanker Dharmais. Depok : Fakultas Ilmu Keperawatan Program Studi Sarjana.

Karima, Asri. (2014). Faktor-Faktor Yang Berhubungan Dengan Stres Kerja Pada Pekerja Di PT X Tahun 2014. Jakarta :UIN Syarif Hidayatullah.

Munthe, Y. M. (2014). Mekanisme Koping Perawat Terkait Konflik Yang Terjadi Di Tempat Kerja Di Ruang Rawat Inap Rumah Sakit Umum Daerah Dr. Djasamen Saragih Pematang Siantar.

Noer Aini (2013). Koping Perawat Terhadap Stress Kerja Di Ruang Rawat Inap (Studi Di Rumah Sakit Telogorejo Semarang)

Nurazizah. (2017). Faktor-Faktor Yang Berhubungan Dengan Stres Kerja Pada Perawat Di Ruanga Rawat Inap RS X Jakarta Tahun 2017

Prasetyo, W. (2017). Literature Review: Stres Perawat Di Ruang Instalasi Gawat Darurat.Jurnal Ners LENTERA, 5(1), 43-55.

Sugeng, Sri Utami, Hadi, Harry Tribowo, \& Nataprawira, Rizky Kurnia. (2015). Gambaran Tingkat Stres Dan Daya Tahan Terhadap Stres Perawat Instalasi Perawatan Intensif Di Rumah Sakit Immanuel

Wulandari, T. (2012). Faktor-Faktor Yang Melatarbelakangi Laki-Laki Berprofesi Sebagai Perawat. Yogyakarta. Universitas Negeri Yogyakarta 